\title{
Awareness of behaviours that cause and alleviate global warming and intention to perform the behaviours among Malaysian educated laypeople
}

\begin{abstract}
Reducing global warming is not simply the domain of government but should start at the individual level, by knowing the right behaviours for mitigating global warming. This study examines Malaysian educated laypersonôs knowledge about global warming and their awareness of behaviours that both cause or alleviate global warming. In this study, a total of 300 participants were asked to list their behaviours which cause global warming and their behaviours they might think reduce global warming. They were then asked to rate their intention regarding these behaviours. Results showed that the respondents were well aware on the effects of air-conditioning and automobiles on global warming but underrated eating meat and using washing machines as causes of global warming, while also misjudging the impact of littering as a cause of global warming. Respondents did well in rating recycling and driving less as a relative impact in reducing global warming but underrated the impact of reducing meat consumption and reduce air travelling as a global warming mitigation. Even though knowledge about behaviours that reduce global warming was not strongly linked to intention to perform the behaviour, the belief in effectiveness that an action that reduces global warming, whether the behaviour is accurate or not, was strongly linked to intention to perform the behaviour.
\end{abstract}

Keyword: Global warming; Effectiveness knowledge; Effectiveness belief 